\title{
Derinin metastatik tümörlerinin primer deri tümörleri arasındaki sıklığı ve klinik özellikleri
}

\author{
The clinical characteristics and the frequency of metastatic cutaneous tumors \\ among primary skin tumors
}

\section{Güldehan Atıș, Gülșen Tükenmez Demirci, İlknur Kıvanç Atunay, Damlanur Sakız*}

Șișli Etfal Eğitim ve Araștırma Hastanesi, Deri ve Zührevi Hastalıklar Kliniği ve *Patoloji Kliniği, İstanbul, Türkiye

Özet

Amacımız: Derinin metastatik tümörlerinin, deri ve deri eki tümörleri arasındaki sıklığını ve klinik özelliklerini tespit etmekti. Gereç ve Yöntem: 2006-2012 yılları arasında histopatolojik inceleme sonucunda deri ve deri eki tümörü tanısı alan tüm hastalar hastanemiz arşivlerinden taranarak tespit edildi. Bu deri tümörleri içerisinden deri metastazı tanısı alan hastaların yaş ve cinsiyeti, internal malignite tanısı, deri lezyonunun tipi, lokalizasyonu ve internal malignite ile ilişkili ortaya çıııs süresi kayıt edildi.

Bulgular: Histopatolojik inceleme sonucunda 4126 deri ve deri eki tümörü tanısı konan biyopsi örneği içerisinden 20 'sinin $(\% 0,48)$ derinin

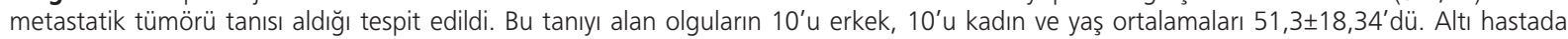
gastrointestinal sistem, 4 hastada akciğer kanseri 4 hastada meme kanseri, 3 hastada malign melanom, 1 hastada Ewing sarkomu 1 hastada akut miyeloblastik lösemi (AML) ve 1 hastada da prostat kanseri derideki metastazın kaynağı olarak tespit edildi. Metastatik deri lezyonlarının 14'ü nodül, 2'si ekzematize plak, 2'si papül, 1'i papülonodül, 1'i infiltre plak şeklindeydi. Metastatik tümörlerin lokalizasyonları incelendiğinde 7 olguda göğüs ön duvarı 5 olguda abdomen, 2 olguda sırt, 2 olguda uyluk 2 olguda saçlı deri, 1 olguda ön kol ve 1 olguda ise inguinal bölge yerleşim bölgesiydi. Sadece 3 olgunun (\%15) internal malignite tanısı öncesinde deri metastazı tanısı aldığı, 17 olgunun (\%75) ise internal malignite tanısından ortalama $18,97 \pm 24,76$ ay (1,5-109 ay) sonra deriye metastaz tanısı aldı̆̆ı tespit edildi.

Sonuç: Derinin metastatik tümörleri nadir rastlanan tümörlerdir. Bu çalışmada deri metastazlarının en sık nodüler lezyonlar şeklinde ve gövde tutulumları ile başvurduğu gözlenmiştir. Bu tümörlerin kaynak aldıkları internal maligniteyi göstermeleri açısından dermatologlar tarafından tanınmaları Önem taşımaktadır. (Türkderm 2013; 47: 166-9)

Anahtar Kelimeler: Kutanöz, metastaz, nodül

\section{Summary}

Background and Design: Our aim was to investigate the clinical characteristics and the rate of metastatic skin lesions among all skin and skin appendage tumors.

Materials and Methods: We scanned the records of the histopathological diagnoses of all the skin tumors from the archives between 2006 to 2012 and recorded the data including age, gender, the diagnosis of internal malignancy, type of the cutaneous lesion, the location and the period between the appearance of the primary malignancies and cutaneous metastases.

Results: We found that $20(0.48 \%)$ of 4126 skin tumors were diagnosed as metastatic skin tumors. Ten patients were men and ten were women (median age: $51.3 \pm 18.34$ ). When considered primary internal malignancies of these patients, 6 patients were diagnosed with gastrointestinal malignancy, 4 - with lung cancer, 4 - with breast cancer, 3 - with malignant melanoma, 1 - with Ewing's sarcoma, 1 - with acute myeloblastic leukemia and 1 patient was diagnosed with prostatic cancer. The clinical appearance of the tumors was as follows: nodule (14), eczematized plaque (2), papule (2), papulonodule (1), and 1 infiltrated plaque (1). The localizations of the metastatic skin lesions were as follows: 7 lesions on the anterior trunk, 5 - in the abdominal wall, 2 - on the back, 2 - on the thigh, 2 - on the scalp, 1 - on the anterior arm, and 1 lesion on the inguinal site. We found that 3 patients (15\%) were diagnosed with metastatic skin tumors before the diagnosis of internal malignancies while 17 patients (85\%) were found to have metastatic skin lesions $18.97 \pm 24.76$ months (1.5-109 months) after the diagnosis of internal malignancies.

Conclusion: Cutaneous metastatic skin tumors are rarely seen skin lesions. We found that cutaneous metastatic skin tumors are mostly nodular and on trunk localization. It is important to recognize these tumors, because they can adress primary internal tumors. (Turkderm 2013; 47: 166-9) Key Words: Cutaneous, metastasis, nodule

Yazışma Adresi/Address for Correspondence: Dr. Güldehan Atış, Şişli Etfal Eğitim ve Araştırma Hastanesi, Deri ve Zührevi Hastalıklar Kliniği, İstanbul, Türkiye Tel.: +90 2123735000 E-posta: guldehan.atis@gmail.com Geliş Tarihi/Received: 25.10.2012 Kabul Tarihi/Accepted: 17.01.2013 


\section{Giriş}

Derinin metastatik tümörleri nadir gözlenen, internal malignite tanısından önce veya herhangi bir zamanda ortaya çıkabilen deri tümörleridir ${ }^{1}$. Internal maligniteli vakaların \%0,7 ile \%10,4'sinde derinin metastatik tümörlerinin gözlendiğine dair çalışmalar mevcuttur². Henüz primer internal malignite tanısı almamış hastalarda metastatik deri tutulumu gözle görülebilir olması ve esas malign tümör için haberci niteliğini taşıması açısından oldukça önem taşımaktadır. Oysa ki çoğu kez nodül veya papül şeklinde ortaya çıktığı gözlenen deri metastazları, bazen hasta bazen de sağlık profesyonelleri tarafından basit görülerek önemsenmemekte ve histopatolojik incelemeye başvurulmadığında ise tanı konması gecikmektedir ${ }^{3}$. Internal malignite tanısı almış olgular dermatologlara başvurduğunda özellikle deri metastazı olasıı̆̆ı akılda tutulmakta ancak, nadir rastlanan bu tümörlerin klinik özellikleri de iyi bilinmediğinden, olgular malignite tanısı almamış ise deride metastaz ön tanısı atlanabilmektedir. Bu araştırmada dermatoloji kliniğine başvurup deri ve deri eki tümörü tanısı alan olgular içerisindeki deri metastazı sıklığının araştırıması, bu tümörlerin klinik ve demografik özelliklerine ek olarak internal malignite tanısı ile deri metastazı tanısı arasındaki zamansal ilişkinin tespit edilmesi amaçlanmıştır.

\section{Gereç ve Yöntem}

2006-2012 yılları arasında polikliniğimize başvuran ve histopatolojik inceleme sonucunda tüm deri ve deri eki tümörü tanısı alan hastalar hastanemiz dermatoloji ve patoloji klinikleri arşivlerinden elektronik ortamda taranarak tespit edildi. Bu deri tümörleri içerisinden; deri metastazı tanısı alan olguların, yaş ve cinsiyeti, internal tümör tanısı, deri lezyonunun tipi, lokalizasyonu ve internal malignite tanısı ile deri metastazının tanı alma zamanı ile ilişkili dosya kayıtları retrospektif olarak incelenerek kaydedildi Primer internal tümörün genişlemesi ile üzerindeki deriyi doğrudan invaze edenler derinin metastatik tümörleri grubunun dışında bırakıldı.

\section{Bulgular}

Histopatolojik inceleme sonucunda 4126 deri ve deri eki tümörü tanısı konan biyopsi örneğinin içerisinden 943 'ü $(\% 22,86)$ primer malign deri ve deri eki tümörü, 3163'ü $(\% 76,66)$ benign deri ve deri eki tümörü iken 20'sinin $(\% 0,48)$ metastatik deri tümörü olduğu tespit edildi . Deri metastazlı olguların, 10'u, erkek, 10'u kadın ve yaş ortalamaları $51,3 \pm 18,34^{\prime}$ dü. Altı hastada gastrointestinal sistem malignitelerinin (3 hastada mide kanseri, 3 hastada kolon kanseri) deride metastazı saptanırken sırasıyla 4 hastada akciğer kanserinin, 4 hastada meme kanserinin, 3 hastada malign melanomun,1 hastada "Ewing" sarkomunun, 1 hastada akut miyeloblastik löseminin (AML) ve 1 hastada da prostat kanserinin deri metastazı saptandı. Kadın olguların 4'ünde meme kanseri (invaziv duktal karsinom), 3'ünde malign melanom, 2'sinde gastrointestinal sistem maligniteleri (1 hastada mide adenokarsinomu, 1 hastada kolon adenokarsinomu), 1'inde akciğer tümörlerine (adenokarsinom) bağlı metastazlar olduğu gözlenirken, erkek olguların 4'ünde gastrointestinal sistem maligniteleri (2 hastada kolon adenokarsinomu, 2 hastada mide adenokarsinomu), 3'ünde akciğer (adenokarsinom, büyük hücreli karsinom), 1'inde prostat (adenokarsinom), 1'inde "Ewing" sarkomu, 1'inde akut miyeloblastik lösemiye ait deri metastazları olduğu gözlendi. Derideki metastatik lezyonların 14 'ü nodül, 2'si ekzematize plak, 2'si papül, 1'i papül ve nodül, $1^{\prime}$ i infiltre plak şeklindeydi. Bu tümörlerin lokalizasyonları ise; 7 olguda göğüs ön duvarı, 5 olguda abdomen, 2 olguda sırt, 2 olguda uyluk, 2 olguda saçı deri, birer olguda da ön kol ve inguinal bölge şeklindeydi. Üç olgunun (\%15) internal malignite (2 meme kanseri, 1 mide kanseri) tanısı öncesinde deriye metastaz tanısı aldığı, 17 (\%75) olgunun ise internal malignite tanısından ortalama $18,97 \pm 24,76$ ay (1,5 -109 ay) sonra deri metastazı tanısı aldığı tespit edildi (Tablo 1).

\section{Tartışma}

Deri metastazları internal malignitelerin \%0,7-10,4'ünde gözlenen nadir bir bulgudur 1,4. Ileri evre malignitenin ya da tedaviye yanıtsızığın göstergesi olarak kabul edilirler1,5. Bazen nadir de olsa internal malignitelerin ilk bulgusu olarak karşımıza çıkabilir, diğer organ metastazlarının da habercisi olabilirler ${ }^{1}$. Literatürde internal maligniteli hastalardaki deri metastazı sıklığını inceleyen çalışmalar bulunmaktadır. Bizim çalışmamız ise metastatik deri tümörlerinin tüm deri ve deri eki tümörleri arasındaki sıklığını inceleyen ilk çalışmadır ve bu oran çalışmamızda \%0,48 olarak tespit edilmiştir.

Gül ve ark. tarafından 1287 internal malignitesi olan hasta grubu ile yapılan çalışmada 15 hastada $(\% 1,16)$ deri metastazı tespit edilmiş ve en sık meme kanserinin ( 5 hastada), sonra sırasıyla hematolojik malignitelerin (4 hastada), akciğer kanserinin (4 hastada) ve gastrointestinal sistem malignitelerinin (2 hastada) deriye metastaz yaptığı gösterilmiştir6. Bizim çalışmamızda da benzer malignitelerin deriye metastaz yaptıkları ortaya konmakla birlikte, en sık malignite olarak ilk sırada gastrointestinal sistem tümörleri ( 6 hasta), ikinci sırada meme kanseri (4 hasta), akciğer kanseri (4 hasta) ve üçüncü sırada malign melanom (3 hasta) tespit edilmiştir. Bansal ve ark. yaptıkları bir çalışmada erkeklerde gastrointestinal tümörlerin, kadınlarda ise meme kanserinin deriye en sık metastaz yapan tümörler olduğu gösterilmiştir. Bizim çalışmamızda da meme kanserinin kadınlarda, gastrointestinal sistem tümörlerinin ise erkeklerde en sık deri metastazı tümörler olduğu tespit edilmiştir7.

Derinin metastatik tümörleri nodül, papül, plak, tümör ve ülserasyon gibi çok farklı lezyonlar şeklinde ortaya çıkabilmektedir. Klinik görünümleri sıklıkla benign deri hastalıklarını taklit etmektedir8,9,10. Lookingbill ve ark. 4020 metastatik malignitesi olan hastalarla yaptıkları çalışmada 420 olguda (\%10) kutanöz metastaz tespit etmişler ve en sık görülen lezyonun nodül olduğunu ortaya koymuşlardı2. Benzer şekilde Gül ve ark. yaptıkları çalışmada da nodüler lezyonların en sık görülen lezyonlar olduğunu göstermişlerdir6. Benmously ve ark. tarafından yapılan çalışmada da nodüler lezyonlar (\%93) kutanöz metastatik tümörlerin en sık gözlenen lezyonudur. Bizim çalışmamızda da nodüler lezyon 13 hastada (\%65) en sık gözlenen lezyon olmuştur ${ }^{11}$

Tümörler sıklıkla son dönemlerinde, tümör hücreleri ve metastaz yaptıkları dokular arasındaki karmaşık etkileşimler sonucu metastaz yapmaktadırlar12. Ancak internal malignitelerin nadiren deriye metastaz yapmasının nedeni halen tam olarak açıklığa kavuşmamıştır. Saçı deriye metastazın daha sık görülmesinin nedeni, vaskülaritesinin fazla olmasıyla açıklanırken, diğer alanlara metastaz doğrudan invazyon, cerrahi ya da tanısal diğer işlemler sırasında iyatrojenik olarak, lenfatik veya hematojen yayılım ile olabilmektedir. Derinin metastatik tümörleri sıklıkla primer internal malignitelere komşu olan alanlarda 
ortaya çıkmaktadır13.Çalışmamızda en sık metastatik deri tümörü lokalizasyonu göğüs ön duvarı (\%35) olarak saptanmıştır. Bunun sebebi meme kanseri ve akciğer kanserli olgu sayısının (\%45) fazla olması ile açıklanabilir. Benzer şekilde Saeed S ve ark. 'larının ${ }^{3}$ yaptıkları çalışmada, gövdenin en sık lokalizasyon (\%40) olduğu saptanırken, Gül ve ark'nın6 çalışmasında göğüs ön duvarı en sık yerleşim yeri olarak bildirilmiştir. Akciğer kanseri sıklıkla göğüs ön duvarı ve üst ekstremitenin proksimal alanlarındaki deriye metastaz yapmaktadır. Bizim çalışmamızda 4 akciğer kanseri tanılı olgunun derideki metastazları 1 vakada göğüs ön duvarında, 1 vakada sırtta, 1 vakada ise sağ kolda idi. Bu lokalizasyonlar doğrudan invazyon ile yayılımı desteklerken, kalan 1 vakada metastatik tümörün saçlı deriye yerleşmesi hematojen yayılımı desteklemektedir. Çalışmamızdaki vakaların 3'ünde kolon adenokarsinomu kaynaklı metastatik tümör lokalizasyonu abdomen derisindedir ve vakaların birinde tümör eski insizyon hattı üzerinde saptanmıştır. Diğer vakalara benzer şekilde doğrudan invazyonun, kolon adenokarsinomunda da deriye metastaz açısından önemli bir yol olduğunu ek olarak iyatrojenik yayııımında gözardı edilmemesi gerektiğini göstermektedir.

Derinin metastatik tümörleri nadiren internal malignitelerin ilk bulgusu olarak karşımıza çıkabilmektedir. Bizım çalışmamızda sadece 3 hastada (\%15) derinin metastatik tümörü tanısı internal maligniteden önce konmuştur. On yedi hastada (\%85) derideki tümörler internal malignitenin tanısından ortalama $18,97 \pm 24,76$ ay (1,5-109 ay) sonra ortaya çıkmıştır. Saeed ve ark. tarafından yapılan çalışmada internal malignitesi olan vakaların \%7,8'sinde derideki metastatik tümörler internal malignite tanısından önce ortaya çıkarken, geri kalan

Tablo 1. Kutane metastatik tümörlerin dağılımı, demografik ve klinik özellikleri

\begin{tabular}{|c|c|c|c|c|c|}
\hline Olgu & $\begin{array}{l}\text { Yaş/ } \\
\text { cinsiyet }\end{array}$ & Lezyon & Lokalizasyon & Kutane metastaz tanı anı & Primer internal malignensi \\
\hline 1 & $69 / K$ & Nodül & Göğüs ön duvarı & Primer tümörden 24 ay sonra & $\begin{array}{l}\text { Mide kanseri } \\
\text { (Adenokarsinom) }\end{array}$ \\
\hline 2 & $39 / K$ & Nodül & Göğüs ön duvarı & Primer tümörden 20 ay sonra & Malign melanom \\
\hline 3 & $54 / E$ & Nodül & Sirt & Primer tümörden 15 ay sonra & $\begin{array}{l}\text { Akciğer kanseri } \\
\text { (Adenokarsinom) }\end{array}$ \\
\hline 4 & $61 / E$ & Nodül & Göğüs ön duvarı & Primer tümörden 8 ay sonra & $\begin{array}{l}\text { Akciğer kanseri } \\
\text { (Büyük hücreli karsinom) }\end{array}$ \\
\hline 5 & $78 / \mathrm{E}$ & Nodül & Abdomen & Primer tümörden 10 ay sonra & $\begin{array}{l}\text { Kolon kanseri } \\
\text { (Adenokarsinom) }\end{array}$ \\
\hline 6 & $57 / E$ & Nodül & İnguinal bölge & Primer tümörden 10 ay sonra & Malign melanom \\
\hline 7 & $42 / K$ & Ekzematize plak & Göğüs ön duvarı & Primer tümörden 15 gün önce & $\begin{array}{l}\text { Meme kanseri } \\
\text { (Invaziv duktal karsinom) }\end{array}$ \\
\hline 8 & $57 / K$ & Nodül & Uyluk & Primer tümörden 18 ay sonra & Malign melanom \\
\hline 9 & $57 / K$ & Nodül & Saçlı deri & Primer tümörden 1,5 ay sonra & $\begin{array}{l}\text { Akciğer kanseri } \\
\text { (Adenokarsinom) }\end{array}$ \\
\hline 10 & $61 / K$ & Infiltre plak & Göğüs ön duvarı & Primer tümörden 10 ay sonra & $\begin{array}{l}\text { Meme kanseri } \\
\text { (Invaziv duktal karsinom) }\end{array}$ \\
\hline 11 & $42 / K$ & Nodül & Abdomen & Primer tümörden 10 ay sonra & $\begin{array}{l}\text { Kolon kanseri } \\
\text { (Adenokarsinom) }\end{array}$ \\
\hline 12 & $61 / K$ & Ekzematize plak & Göğüs ön duvarı & Primer tümörden 3 ay önce & $\begin{array}{l}\text { Meme kanseri } \\
\text { (Invaziv duktal karsinom) }\end{array}$ \\
\hline 13 & $67 / K$ & Papül & Göğüs ön duvarı & Primer tümörden 7 ay sonra & $\begin{array}{l}\text { Meme kanseri } \\
\text { (Invaziv duktal karsinom) }\end{array}$ \\
\hline 14 & $47 / E$ & Nodül & Abdomen & Primer tümörden 5 ay sonra & $\begin{array}{l}\text { Kolon kanseri } \\
\text { (Adenokarsinom) }\end{array}$ \\
\hline 15 & $57 / E$ & Nodül & Ön kol & Primer tümörden 8 ay sonra & $\begin{array}{l}\text { Akciğer kanseri } \\
\text { (Adenokarsinom) }\end{array}$ \\
\hline 16 & 18/E & Nodül & Sirt & Primer tümörden 36 ay sonra & Ewing sarkom \\
\hline 17 & $51 / E$ & Nodül & Saçlı deri & Primer tümörden 1 ay önce & $\begin{array}{l}\text { Mide kanseri } \\
\text { (Adenokarsinom) }\end{array}$ \\
\hline 18 & 28/E & Papül & Abdomen & Primer tümörden 7 ay sonra & Mide kanseri (Adenokarsinom) \\
\hline 19 & $5 / E$ & Infiltre plaklar & Abdomen & Primer tümörden 24 ay sonra & AML \\
\hline 20 & $75 / E$ & Papül, nodül & Uyluk & Primer tümörden 109 ay sonra & $\begin{array}{l}\text { Prostat kanseri } \\
\text { (Adenokarsinom) }\end{array}$ \\
\hline
\end{tabular}


vakalarda da derideki tümörlerin ortaya çııış süresi, internal malignite tanısından ortalama 33 ay sonra (<1 ay-8 yıl) olmuştur. Gül ve ark. 3 tarafından yapılan çalışmada derideki tümörler 15 hastanın 2'sinde internal malignite tanısından önce, 13 hastada internal malignite tanısından sonra gözlenirken, ortaya çıkış süresi 2 ay ile 84 ay arasında değişmektedir. Literatürdeki sürelerin değişkenlik göstermesi, nadir görülen metastatik deri tümörlerinin tanısının zor konulması veya lezyonların gözden kaçması ile açıklanabilir.

\section{Sonuç}

Derinin metastatik tümörleri, dermatoloji pratiğinde dermatologların nadir karşılaştıkları lezyonlar olmakla birlikte, çoğu zaman basit bir nodül özelliği taşımaları nedeniyle gözden kaçabilmektedir. Bu araştırmada metastatik deri tümörleri, tüm deri ve deri eki tümörlerinin içerisinde $\% 0,48$ oranında bulunmuştur. Bu tümörlerin en sık nodül ve göğüs ön duvarında lokalize olduğu dikkat çekmiştir. Tüm metastatik deri tümörlerinin \%15'ine internal malignite tanısı öncesinde tanı konabilmiştir. Derinin metastatik tümörleri nadir olsa dahi primer internal malignitelerin ilk bulgusu olarak ortaya çıkmaları nedeniyle bu lezyonların dermatologlarca tanınmasının yaşamsal öneme sahip olduğu akılda tutulmalı ve uyanık olunmalıdır.

\section{Kaynaklar}

1. Chopra R, Chhabra S, Samra SG, et al: Cutaneous metastases of internal malignancies: a clinicopathologic study. Indian J Dermatol Venereol Leprol 2010; 76:125-31.
2. Lookingbill DP, Spangler N, Helm KF: Cutaneous metastases in patients with metastatic carcinoma: a retrospective study of 4020 patients. J Am Acad Dermatol 1993;29:228-36.

3. Saeed S, Keehn CA, Morgan MB: Cutaneous metastasis: a clinical, pathological, and immünohistochemical appraisal. J Cutan Pathol 2004;31:419-30.

4. Nashan D, Meiss F, Braun-Falco M, Reichenberger S: Cutaneous metastases from internal malignancies. Dermatol Ther 2010;23:567-80.

5. Song Z, Lin B, Shao L, Zhang Y: Cutaneous metastasis as a initial presentation in advanced non-small cell lung cancer and its poor survival prognosis. J Cancer Res Clin Oncol 2012;138:1613-7.

6. Gül U, Kiliç A, Gönül M, Külcü Cakmak S, Erinçkan C: Spectrum of cutaneous metastases in 1287 cases of internal malignancies: a study from Turkey. Acta Derm Venereol 2007;87:160-2.

7. Bansal R, Naik R: A study of 70 cases of cutaneous metastases from internal carsinoma. J Indian Med Assoc 1998;96:10-2.

8. Sariya D, Ruth K, Adams-McDonnell R, et al: Clinicopathologic correlation of cutaneous metastases: experience from a cancer center. Arch Dermatol 2007;143:613-20.

9. Riahi RR, Cohen PR: Clinical manifestations of cutaneous metastases: a review with special emphasis on cutaneous metastases mimicking keratoacanthoma. Am J Clin Dermatol 2012;13:103-12.

10. Alcaraz I, Cerroni L, Rütten A, Kutzner H, Requena L: Cutaneous metastases from internal malignancies: a clinicopathologic and immünohistochemical review. Am J Dermatopathol 2012;34:347-93.

11. Benmously $R$, Souissi $A$, Badri $T$, et al: Cutaneous metastases from internal cancers. Acta Dermatovenerol Alp Panonica Adriat 2008;17:167-70.

12. Hu SC, Chen GS, Wu CS, et al: Rates of cutaneous metastases from different internal malignancies: experience from a Taiwanese medical center. J Am Acad Dermatol 2009;60:379-87.

13. Weedon D: Cutaneous metastases. Weedon's skin pathology. Ed. Weedon D. $3^{\text {rd }}$ ed. Elsevier, 2010;927-36. 